\title{
Characteristics of the lower ablation zone of the West Greenland ice sheet for energy-balance modelling
}

\author{
Michiel VAN DEN BROEKE* \\ Institute for Marine and Atmospheric Research Utrecht, P.O. Box 80.005, 3508 TA Utrecht, The Netherlands
}

\begin{abstract}
In this paper, we present the summer-time energy balance for a site in the lower ablation zone of the West Greenland ice sheet. The summer climate of this part of Greenland is sunny and dry. The energy that is available for melting (on average $174 \mathrm{~W} \mathrm{~m}^{-2}$ or $4.5 \mathrm{~cm}$ w.e. $\mathrm{d}^{-1}$ ) is mainly provided by net global radiation (twothirds) and sensible-heat flux (one-third). The contribution of the sub-surface heat flux, the latent-heat flux and the net longwave radiation to the energy balance are small. We tested some parameterizations to calculate energy-balance components that are currently used in general circulation models, energy-balance models and mesoscale meteorological models. For the area and time period under consideration, parameterizations that use screen-level temperature for the calculation of incoming longwave radiation systematically underestimate this quantity by $10 \mathrm{~W} \mathrm{~m}^{2}$ owing to the proximity of the melting-ice surface that restricts temperature increase of the lowest air layers. The incoming global radiation was predicted correctly. Simple explicit schemes that calculate the stability corrections for turbulent fluxes as a function of the bulk Richardson number tend to underestimate the turbulent fluxes by $15 \mathrm{~W} \mathrm{~m}{ }^{2}$. The aerodynamic roughness length $z_{0}$ derived from wind-speed profiles appears to be erroneously small, leading to underestimation of the fluxes by $30 \mathrm{~W} \mathrm{~m}{ }^{2}$. Probably, the wind profile is distorted by the rough terrain. An estimate of $z_{0}$ based on microtopographical survey yielded a more realistic result. Because all errors work in the same direction, the use of some of the parameterizations can cause serious underestimation of the melting energy.
\end{abstract}

\section{INTRODUGTION}

About half of the yearly mass loss of the Greenland ice sheet, approximately $500 \mathrm{~km}^{3}$, is due to melting at the surface and run-off (Oerlemans, 1993). A wide range of models and associated parameterizations is currently used to simulate the mass and energy balance of the Greenland ice sheet, ranging from global-scale general circulation models (Ohmura and Wild, 1995), energy-balance models (Wal and Oerlemans, 1994) to detailed mesoscale meteorological models (Meesters and others, 1994; Gallée and others, 1995). If we want to model the ice-sheet response to climate change accurately, it is necessary to measure the distribution of the energy-balance components throughout the melting areas. In West Greenland, several groups measured the energy-balance components close to the equilibrium line: the ETH from Zürich at $69^{\circ} 34^{\prime} \mathrm{N}$ (1155 m a.s.l.; Greuell and Konzelmann, 1994) and the Free University of Amsterdam at $67^{\circ} 02^{\prime} \mathrm{N}$ $(1520$ ma.s.l.; Henneken and others, 1994). Ambach (1977) performed detailed micrometeorological measurements in the higher ablation zone at $69^{\circ} 40^{\prime} \mathrm{N}$ (Camp IV,

\footnotetext{
* Present address: Norsk Polarinstitutt, Postboks 5072 Majorstua, N-0301 Oslo, Norway.
}

1013 ma.s.l.). Recently, energy-balance measurements have been performed in Kronprins Christian Land, northeast Greenland $\left(79^{\circ} 54^{\prime} \mathrm{N}\right)$ at the low elevation of $380 \mathrm{~m}$ a.s.l. (Konzelmann and Braithwaite, 1995). Due to the difficult terrain (crevasses, high seasonal melt), only a few experiments have been carried out in the lower ablation zone in West Greenland. Braithwaite and Olesen (1990) estimated the energy balance at two outlet glaciers in south (Nordboglacier, $880 \mathrm{~m}$ a.s.l.) and West Greenland (Qamanârssûp sermia, $790 \mathrm{~m}$ a.s.l.). This paper presents the distribution of the energy-balance components in the lower melting zone of the Greenland ice sheet ( $340 \mathrm{~m}$ a.s.1.) close to Sondre Stromfjord, $67^{\circ} \mathrm{N}, 50^{\circ} \mathrm{W}$, and can be regarded as an extension to earlier work with data collected at this location (Duynkerke and Broeke, 1994; Wal and Russell, 1994). The measurements were made during two expeditions, GIMEX-90 and 91 (Greenland Ice Margin Experiment). Besides presenting the actual energy balance, an important part of this paper is devoted to the comparison of measurements with parameterizations.

\section{DATA GOLLEGTION}

During GIMEX, data have been collected during $86 \mathrm{~d}$ in two summers, 18 July-17 August 1990 and 10 June-31 


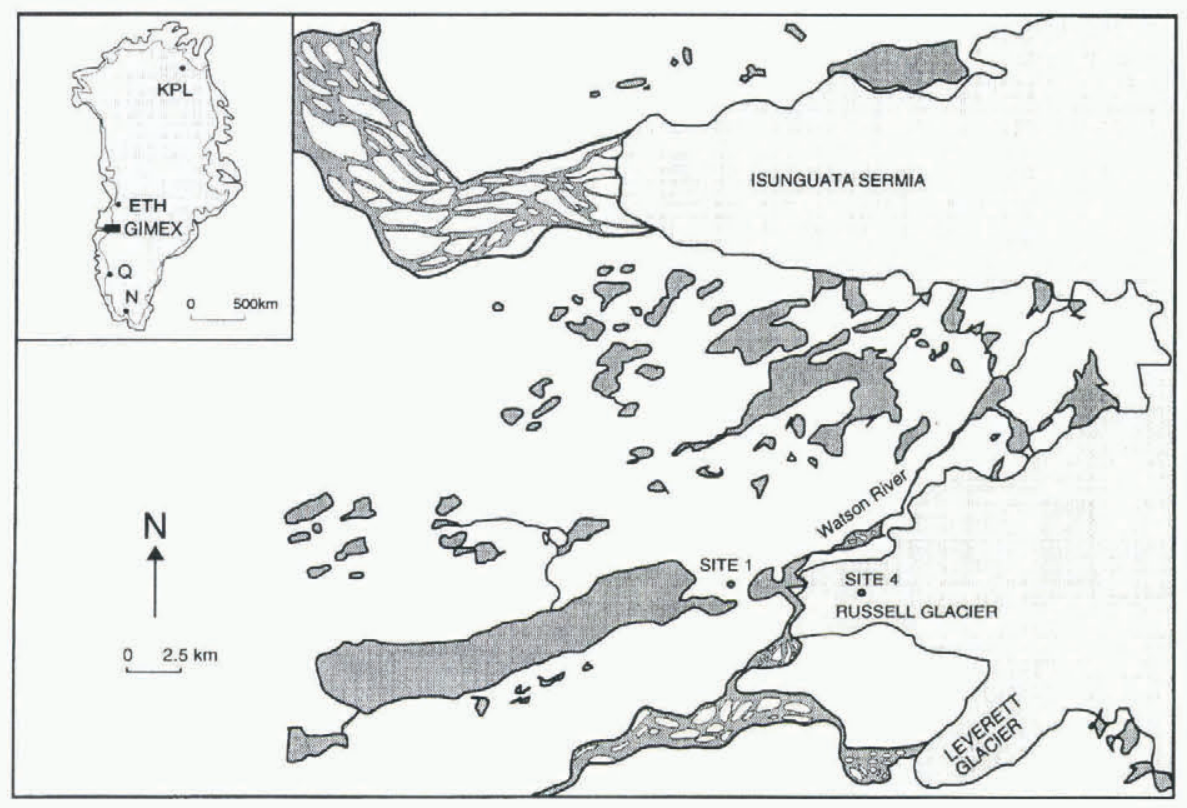

Fig. 1. Location of sites 1 and 4 during GIMEX. Dark-shaded areas represent lakes, light-shaded areas represent the ice surface. The inset shows some of the locations that are mentioned in the text: ETH, ETH camp; KCL, Kronprins Christians Land; N, Nordboglacier; Q Qamanârssüp sermia. Not included in the figure are Camp IV, which was located close to the ETH camp and the Free University of Amsterdam, located at $88 \mathrm{~km}$ from the ice edge in the GIMEX profile.

July 1991, at seven sites along a line crossing tundra and glacier. In this study, we will use mainly data collected at "site 4" on Russell Glacier, $2.5 \mathrm{~km}$ from the boundary between glacier and tundra at an elevation of $340 \mathrm{~m}$ a.s.l. in the area of Sondre Stromfjord (Kangerlussuaq) (Fig. 1). The glacier surface at this spot is very rough: the regularly spaced ice hills have typical dimensions of several metres vertically and horizontally. This and the high seasonal melt rate $(3.1 \mathrm{~m}$ w.e.; $\mathrm{Wal}$ and others, in press) prohibits the operation of tall masts and sensitive equipment. Instead, we used a $6 \mathrm{~m}$ mast with three measurement levels for wind speed, temperature and relative humidity $(0.5,2$ and $6 \mathrm{~m})$. The mast rests freely on the ice with its four legs and melts down with the surface in the course of the ablation season. Temperature and humidity sensors were ventilated. Wind direction was measured at $6 \mathrm{~m}$, while incoming- and outgoing-radiation components were measured at $1.5 \mathrm{~m}$. Global and total incoming and reflected radiation were measured at $1.5 \mathrm{~m}$. After the experiment, the radiation sensors were recalibrated and corrections of sensitivity as well as offset had to be applied before they could be analysed.

Ablation measurements were undertaken at three places in the close vicinity of site 4 , and inter-stake variations for the period under consideration were typically less than $10 \mathrm{~cm}$ or $5 \%$ (Wal and others, in press). On a hill top just in front of the ice margin, a similar mast was erected (site 1, $300 \mathrm{~m}$ a.s.l.; Fig. 1), which should be more or less representative for freeatmosphere conditions at the same elevation as site 4 . Data from this mast will be used to estimate the inversion strength at site 4 in the section dealing with longwave radiation. Cloudiness type and cover) was observed every $3 \mathrm{~h}$.

Table 1 gives some average values at site 4 during GIMEX-91. The temperature at $2 \mathrm{~m}, T_{2 \mathrm{~m}}$, was continuously above the melting point. The wind is clearly of

katabatic nature, blowing from the ice sheet with very high directional constancy $d c$ and a typical speed $V_{6 \mathrm{~m}}$ of $5 \mathrm{~m} \mathrm{~s}^{-1}$. Summer conditions in this part of Greenland are generally sunny and warm, with a mean cloud cover $n=0.5$, resulting in high mean values of incoming shortwave $\left(S h w_{\text {in }}\right)$ and longwave radiation $\left(L w_{\text {in }}\right)$. The surface albedo $\alpha$ is relatively high for ice with $55 \%$. A general description of the experiment has been given by Oerlemans and Vugts (1993). A more detailed description of the climate of the ablation zone can be found in Broeke and others, (1994a). Several papers on GIMEX have been published in a special issue of Global and Planetary Change (No. 9, 1994).

\section{GLOBAL RADIATION}

Accuracy of the daily mean global-radiation measure-

Table 1. Average characteristics at site 4 for the period 10 fune-31 July 1991, based on daily mean values; symbols are explained in the text

Parameter

$\begin{array}{lc}T_{2 \mathrm{~m}} & 4.7^{\circ} \mathrm{C} \\ \text { Min } & 2.2^{\circ} \mathrm{C} \\ \text { Max } & 7.0^{\circ} \mathrm{C} \\ V_{6 \mathrm{~m}} & 5.1 \mathrm{~m} \mathrm{~s}^{-1} \\ d c & 0.94 \\ n & 0.5 \\ S h w_{\text {in }} & 273 \mathrm{~W} \mathrm{~m}^{-2} \\ \alpha & 0.55 \\ L w_{\text {in }} & 287 \mathrm{~W} \mathrm{~m}^{2}\end{array}$




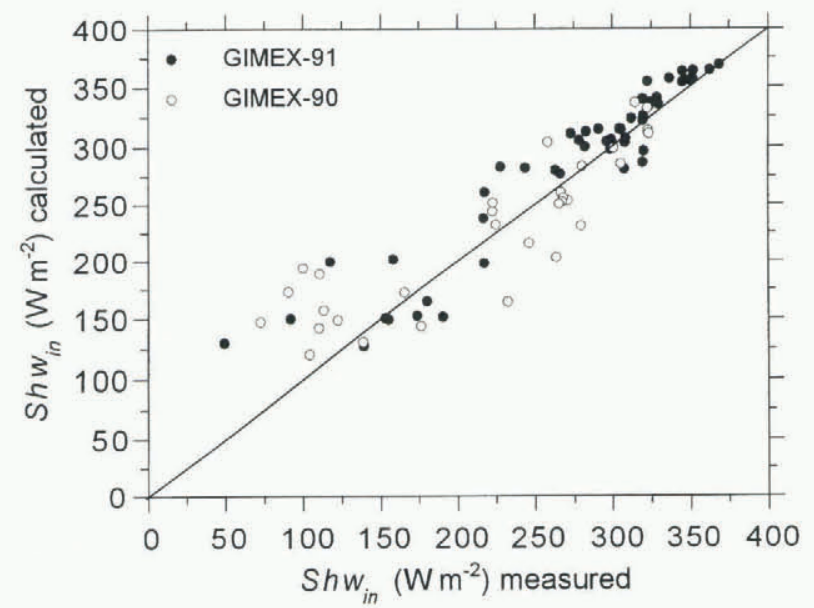

Fig. 2. Daily mean observed vs calculated global radiation. $S h w_{\text {in }}$ at site 4 for GIMEX-90 (open dots) and GIMEX-91 (solid dots). The Shwin calculation is according to the parameterization of Konzelmann and others (1994).

ments after recalibration is estimated to be typically better than $10 \mathrm{~W} \mathrm{~m}^{-2}$. Konzelmann and others (1994) presented a parameterization of the global radiation for the Greenland ice sheet as a function of several variables, of which the most important are date, elevation, cloud cover and surface albedo. In this method, no distinction is made between different cloud types but cloud transmission is made a function of elevation to account for the thinner clouds that are more frequently observed high above the ice sheet. Daily mean values of measured and parameterized global radiation during GIMEX-90 and 91 are given in Figure 2. Note that GIMEX-91 data are not independent, because they have been used to make the parameterization. However, the (independent) data collected during GIMEX-90 show a similarly satisfactory fit. The scatter increases for low values, which is caused by the strongly varying optical thickness of overcast skies, a factor that is not accounted for in the parameterization. Although the distance of the individual points to the $1: 1$ line can be quite large (standard deviation of the

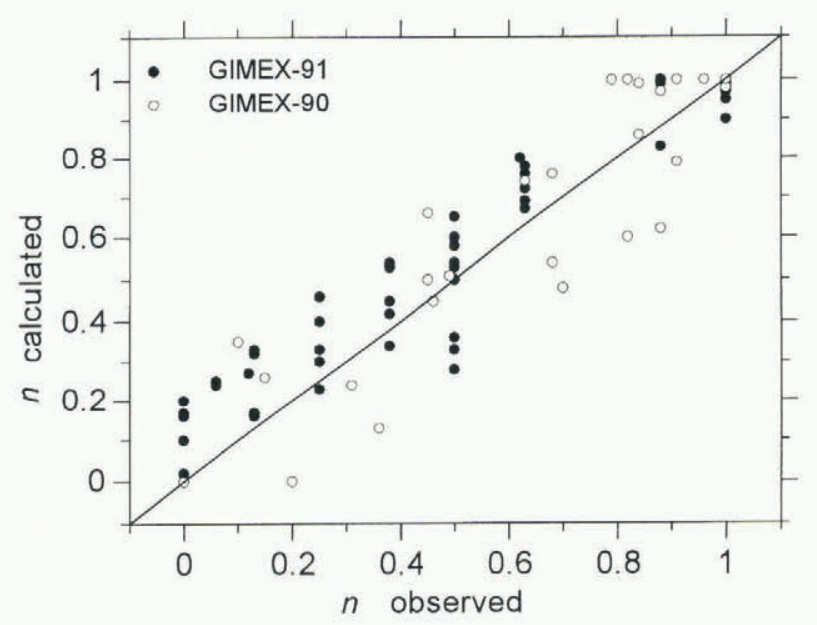

Fig. 3. Daily mean observed vs calculated cloud cover $n$ at site 4 GIMEX-90 (open dots) and GIMEX-91 (solid dots). The calculation is according to the inverse parameterization of Konzelmann and others (1994).
GIMEX-90 daily means: $40 \mathrm{~W} \mathrm{~m}^{2}$ ), the difference between the period means is acceptable, $8 \mathrm{~W} \mathrm{~m}^{-2}$ or $4 \%$. If global radiation is measured, the inverse form of the parameterization can be used to calculate cloud amount $n(0<n<1$; Fig. 3$)$. Difference between measured and calculated cloud amount for the GIMEX-90 data is only $2 \%$, with a standard deviation of $14 \%$, which is accurate enough for the calculation of the incoming longwave radiation (see next section). The results show that this kind of parameterization can also be used for the distinction between cloud cover and a snow surface for satellite pictures, i.e. to judge from automatic weatherstation data whether there is a cloud cover present or not in a certain area.

\section{LONGWAVE RADIATION}

Longwave radiation was not measured directly but estimated by subtracting the global (shortwave) from the total radiation. This procedure, together with the typical measuring accuracy of the sensors, yields an estimated accuracy of the measured daily mean incoming longwave radiation $L w_{\text {in }}$ of $15 \mathrm{~W} \mathrm{~m}^{-2}$. We compared the measurements with the results of two parameterizations for incoming longwave radiation: Konzelmann and others (1994) proposed a parameterization of $L w_{\text {in }}$ for the Greenland ice sheet as a function of $T_{2 \mathrm{~m}}$, watervapour pressure $e_{2 \mathrm{~m}}$ and cloud amount $n$ (Equation (1)), based on measurements undertaken at the ETH camp $\left(69^{\circ} 34^{\prime} \mathrm{N}, 1155 \mathrm{~m}\right.$ a.s.l.). König-Langlo and Augstein (1994) proposed a similar expression based on measurements undertaken at the polar stations Koldewey on Svalbard and Georg von Neumayer in Antarctica (Equation (2)), without inclusion of $e_{2 \mathrm{~m}}$ :

$$
\begin{aligned}
& L w_{\text {in }}=\varepsilon_{\text {eff }} \sigma T_{2 \mathrm{~m}}^{4}=\left[\varepsilon_{\mathrm{cs}}\left(e_{2 \mathrm{~m}}, T_{2 \mathrm{~m}}\right)\left(1-n^{3}\right)+\varepsilon_{\mathrm{oc}} n^{3}\right] \sigma T_{2 \mathrm{~m}}^{4} \\
& L w_{\text {in }}=\varepsilon_{\text {eff }} \sigma T_{2 \mathrm{~m}}^{4}=\left[\varepsilon_{\mathrm{cs}}+0.22 n^{3}\right] \sigma T_{2 \mathrm{~m}}^{4}
\end{aligned}
$$

where $\varepsilon_{\text {eff }}, \varepsilon_{\mathrm{cs}}$ and $\varepsilon_{\mathrm{oc}}$ are the effective, clear-sky and overcast emissivity of the atmosphere, respectively, and $\sigma$

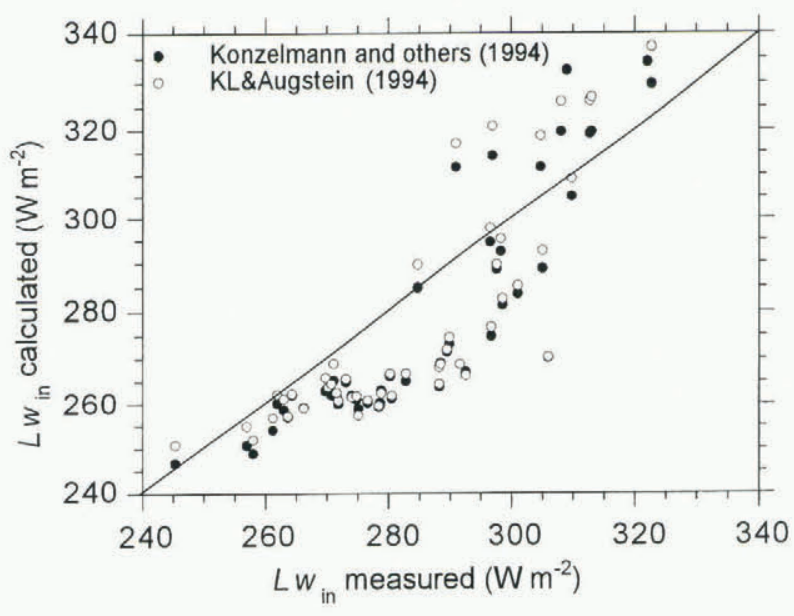

Fig. 4. Daily mean observed vs calculated incoming longwave radiation $L w_{\text {in }}$ at site 4 during GIMEX-91. The $L w_{\text {in }}$ calculation is according to the parameterization of Konzelmann and others (1994) (solid dots) and König-Langlo and Augstein (1994) (open dots). 


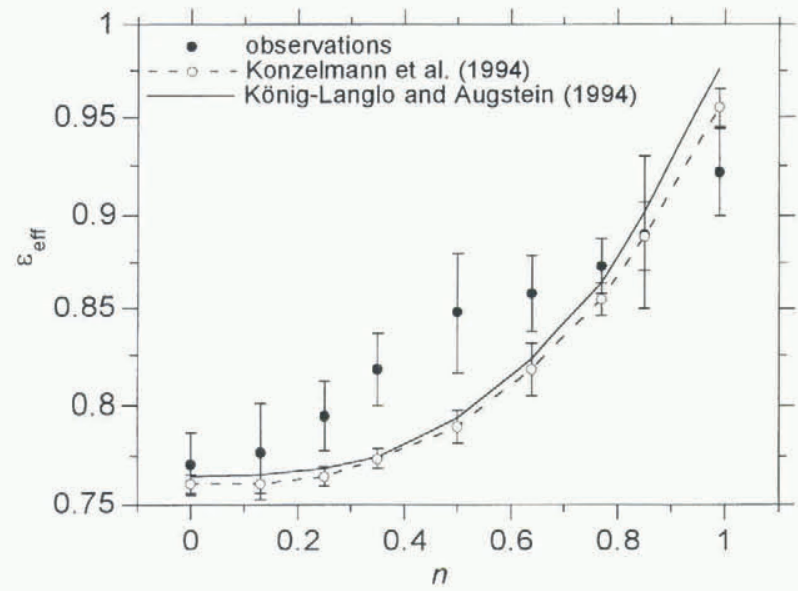

Fig. 5. Observed and calculated effective emissivity $\varepsilon_{\text {eff }}$ vs cloud amount intervals $n$ at site 4 during GIMEX-91. The calculations are according to the parameterization of Konzelmann and others (1994) (dashed line) and KönigLanglo and Augstein (1994) (solid line). Error bars in the curve of Konzelmann and others (1994) represent the standard deviation due to water-vapour pressure.

the Stefan-Boltzmann constant. Figure 4 compares the measured and calculated $L w_{\text {in }}$ for GIMEX-91. Between 260 and $300 \mathrm{~W} \mathrm{~m}^{-2}$, the calculated $L w_{\text {in }}$ systematically underestimates the measured $L w_{\text {in }}$ by $20-30 \mathrm{Wm}^{-2}$. This can be ascribed to the use of $T_{2 \mathrm{~m}}$ in Equations (1) and (2), which is not a reliable measure for the temperature of the lower atmosphere above a melting ice or snow surface. Due to the strong surface inversion, especially in the lower parts of the ice sheet, it will systematically yield too low values. The damping effect of the melting ice on the temperature near the surface is illustrated by the small range of daily mean $T_{2 \mathrm{~m}}$ during GIMEX-91 $(5.5 \mathrm{~K})$, while the measured values of $L w_{\text {in }}$ during clear-sky conditions represent a range of clear-sky radiation temperature of $9.3 \mathrm{~K}$. The systematic underestimation of $\mathrm{Lw}_{\text {in }}$ for temperatures above freezing can also be traced back in the graphs on which the parameterizations on which Equations (1) and (2) are based, i.e. Figure 13 in Konzelmann and others (1994) and Figure 1 in KönigLanglo and Augstein (1994). For higher values of $L w_{\text {in }}$ $\left(>300 \mathrm{~W} \mathrm{~m}^{-2}\right)$, strong large-scale winds effectively mix down the warm air, thereby decreasing the inversion strength. Under these conditions both parameterizations yield better results.

Figure 5 shows the effective emissivity $\varepsilon_{\text {eff }}$ averaged over intervals of cloud amount $n$. The differences between the two parameterizations are small, although the expression of Konzelmann and others (1994) yields slightly better results for high cloud amounts owing to the inclusion of $\varepsilon_{\mathrm{oc}}$ in their expression. The error bars for the Konzelmann data arise from the inclusion of the water-vapour pressure in their parameterization. For strong inversion cases, $\varepsilon_{\text {eff }}$ is significantly too low in both expressions. Figure 6 shows the difference of $L w_{\text {in }}$ between parameterization and measurements as a function of temperature difference between sites 1 and 4, which can be regarded as a measure of the temperature inversion above the melting ice. It appears that an increasing inversion strength causes an increasing error in the calculated value of $L w_{\text {in }}$ at an approximate rate of
$10 \mathrm{~W} \mathrm{~m}^{2} \mathrm{~K}^{-1}$ for both parameterizations. Especially, for ice bodies in warm environments, this could lead to serious errors in estimates of $L w_{\text {in }}$. In the case of GIMEX91, the maximum error is $20-30 \mathrm{~W} \mathrm{~m}^{-2}$.

\section{TURBULENT FLUXES}

The turbulent fluxes of sensible and latent heat $(H, L E)$ were calculated from mean variables measured at one level $(6 \mathrm{~m})$ and by assuming that the surface was melting, as described by Munro (1989). This method has the advantage that the surface values for temperature and moisture are well known and the differences between the levels are larger than between two levels in the atmosphere. The surface layer above a melting glacier is continuously stably stratified, so turbulence is suppressed by the stratification. To calculate the stability correction of the turbulent fluxes, we compared two different methods. The first method uses the well-known expressions according to Monin Obukhov (M.O.) similarity theory (see, e.g., Duynkerke and Broeke, 1994):

$$
\begin{aligned}
H & =\rho c_{\mathrm{p}}\left(w^{\prime} \theta^{\prime}\right)_{\mathrm{s}}=-\rho c_{\mathrm{p}} u_{*}\left(\frac{z}{L}\right) \theta_{*}\left(\frac{z}{L}\right) \\
L E & =\rho L_{\mathrm{v}} \overline{\left(w^{\prime} q^{\prime}\right)_{\mathrm{s}}}=-\rho L_{\mathrm{v}} u_{*}\left(\frac{z}{L}\right) q_{*}\left(\frac{z}{L}\right) \\
L & =\frac{u_{*}^{2}}{\kappa\left(g / \theta_{\mathrm{r}}\right)\left(\theta_{*}+0.62 \theta_{\mathrm{r}} q_{*}\right)}
\end{aligned}
$$

where $\rho$ is the air density, $c_{\mathrm{p}}$ is the specific heat of air at constant pressure, $L_{\mathrm{v}}$ is the latent heat of vaporisation, $z$ is the measurement height, $L$ is the Monin-Obukhov length, $w^{\prime}, \theta^{\prime}$ and $q^{\prime}$ are the turbulent fluctuations of wind, temperature and humidity, and $u_{*}, \theta_{*}$ and $q_{*}$ are the associated turbulent scales, which are functions of the dimensionless stability parameter $z L^{-1}, \kappa$ is the von Kármán constant, $g$ is the acceleration of gravity and $\theta_{\mathrm{r}}$ is a reference temperature. The stability functions are taken

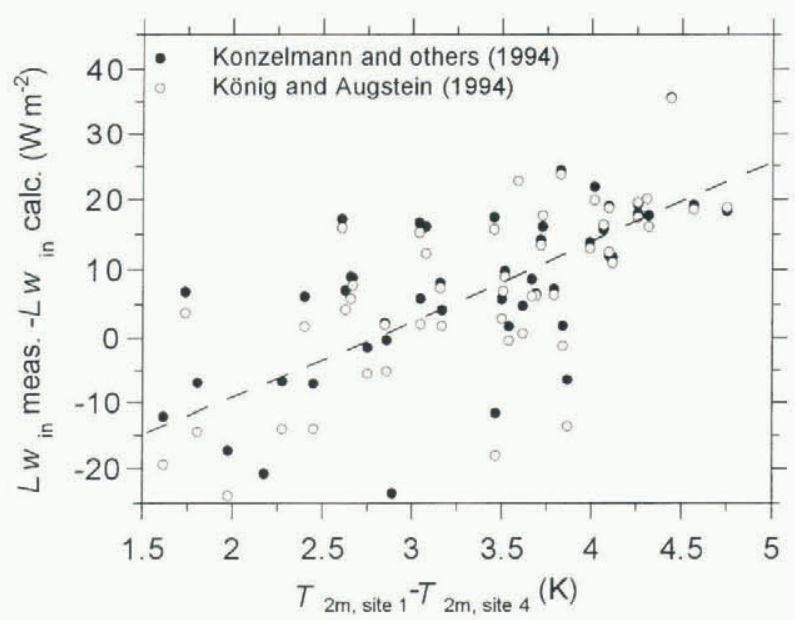

Fig. 6. Difference between measured and calculated mean $L w_{\text {in }}$ at site 4 us potential temperature difference between sites 1 and 4 during GIMEX-91, according to the parameterization of Konzelmann and others (1994) (solid dots) and König-Langlo and Augstein (1994) (open dots). The temperature difference is assumed to be a measure of the surface inversion at site 4. 
Table 2. Average sensible-heat flux $H\left(\mathrm{Wm}^{2}\right)$ for the period 15 June-31 July 1991. Stability corrections are discussed in the text. Percentage between brackets is the reduction of $H$ when compared to the neutral (uncorrected) value

\begin{tabular}{lll}
\hline Stability correction & $z_{0}=0.08 \mathrm{~cm}$ & $z_{0}=12 \mathrm{~cm}$ \\
\hline None (neutral) & $56(0 \%)$ & $67(0 \%)$ \\
$\mathrm{M} . \mathrm{O}$. & $28(50 \%)$ & $58(13 \%)$ \\
$\mathrm{Ri}_{\mathrm{b}}$ & $36(36 \%)$ & $43(36 \%)$ \\
\hline
\end{tabular}

from Duynkerke (1991) and will not be given here. Because $z L^{-1}$ in its turn depends on the surface fluxes, this calculation method requires an iterative procedure (implicit method).

Secondly, we will try a simpler, explicit stability correction originally proposed by Louis (1979). This expression is often used in meteorological models for its computational efficiency Greuell and Konzelmann, 1994; Meesters and others, 1994). The fluxes for the neutral case $\left(z L^{-1}=0\right)$ are multiplied by a factor $f_{\mathrm{s}}$ that accounts for stability effects $\left(0<f_{\mathrm{s}}<1\right.$ for stable conditions):

$$
\begin{aligned}
H & =-\rho c_{\mathrm{p}} f_{\mathrm{s}} u_{*}\left(\frac{z}{L}=0\right) \theta_{*}\left(\frac{z}{L}=0\right) \\
L E & =-\rho L_{\mathrm{v}} f_{\mathrm{s}} u_{*}\left(\frac{z}{L}=0\right) q_{*}\left(\frac{z}{L}=0\right) \\
f_{\mathrm{s}} & =\left(1+15 \operatorname{Ri}_{\mathrm{b}} \sqrt{1+\operatorname{Ri}_{\mathrm{b}}}\right)^{-1}
\end{aligned}
$$

where $\mathrm{Ri}_{\mathrm{b}}$ is the bulk Richardson number, that can be calculated explicitly from the measurements:

$$
\mathrm{Ri}_{\mathrm{b}}=\frac{g}{\theta_{0}} \frac{\left(\theta_{z}-\theta_{\mathrm{s}}\right) z}{V_{z}^{2}}
$$

in which $V$ is the wind speed and the subscript s refers to the surface values. This method will be referred to as the " $\mathrm{Ri}_{\mathrm{b}}$ correction".

For both methods, we still must specify at which height the profiles of wind, temperature and moisture attain their surface values. At $z=z_{0}$, the surface-roughness length for momentum, the wind speed extrapolates to zero. The roughness length for heat and moisture $z_{\mathrm{h}}$ is a function of the flow and can be calculated using the expression developed by Andreas (1987) that expresses $z_{\mathrm{h}}$ as a function of the roughness Reynolds number, $\operatorname{Re}=u^{*} z_{0} \nu^{-1}$, where $\nu$ is the kinematic viscosity of air and $u^{*}$ is the friction velocity. We tried two different values of $z_{0}$ : a value obtained from wind profiles $\left(z_{0}=0.08 \mathrm{~cm}\right.$; Duynkerke and Broeke, 1994) and one obtained from microtopographical survey $\left(z_{0}=12 \mathrm{~cm}\right)$ according to the method described by Lettau (1969). The results for the sensible-heat flux $H$ during GIMEX-91 are summarized in Table 2; the average latent-heat flux $L E$ was negligibly small for all experiments $\left(<1 \mathrm{~W} \mathrm{~m}^{2}\right)$ and is not shown here.

The $\mathrm{Ri}_{\mathrm{b}}$ stability correction assumes a typical value of the surface roughness (lower than is encountered at site 4) and reduces the "neutral" flux by $36 \%$. This appears to be an unjustified simplification, given the very different results obtained with the physically more realistic M.O. theory. This can be understood as follows: in the stable surface layer, turbulence is generated mainly by wind shear which, of course, strongly depends on the surface roughness. Consequently, the explicit method overestimates the flux reduction above a rough surface in stable conditions, leading to underestimation of the turbulent fluxes.

\section{EFFECTS OF THE USE OF DIFFERENT PARA- METERIZATIONS ON THE CALCULATED AMOUNT OF MELT}

The energy balance above a melting ice surface can be written as:

$$
M=S h w_{\text {in }}(1-\alpha)+L w_{\text {in }}-L w_{\text {out }}+H+L E+G
$$

where $M$ is the melting energy. In all subsequent calculations we have neglected the contribution of the sub-surface heat flux, $G$, i.e. the sub-surface layers are assumed to be isothermal at $0^{\circ} \mathrm{C}$. This assumption is justified for the lower ablation zone in the high summer (Ambach, 1977). Using some of the parameterizations and assumptions discussed in the previous sections, we calculated the melt $M$ and compared it to the measured ablation. Figure 7 shows the calculated and observed amount of melt for the period 15 June-31 July 1991, based on the use of the different parameterizations. The error bars for the ablation measurements represent the typical $5 \mathrm{~cm}$ standard deviation of the ablation measurements between the three stakes. Figure 7 shows that the measured ablation of $2070 \mathrm{~mm}$ w.e. is predicted accurately within $2 \%$ (upper line) if we use the measured values of $S h w_{\text {in }}$ and $L w_{\text {in }}$, the value of $z_{0}$ obtained by microtopographical survey $(12 \mathrm{~cm})$ and the stability correction according to M.O. similarity theory. Using the parameterization (1) to calculate $L w_{\text {in }}$ and assuming a melting surface to calculate $L w_{\text {out }}$ yields a shortage of

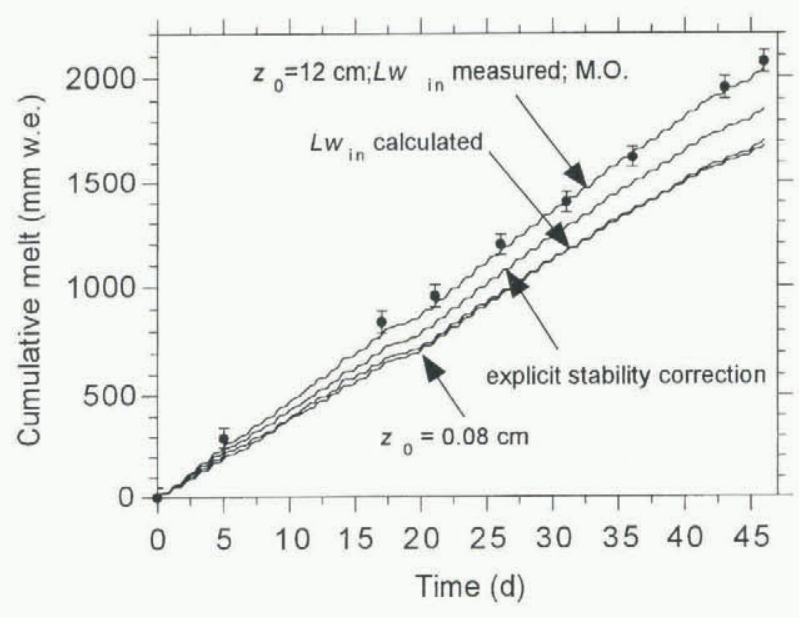

Fig. 7. Calculated (lines) and observed (solid dots) cumulative melt (mmw.e.) at site 4 during GIMEX-91, based on hourly mean values. Error bars represent typical standard deviation of the ablation measurements. Note the clear daily cycle in the calculated melt curves, which is due to the pronounced daily cycle in the melting energy. 


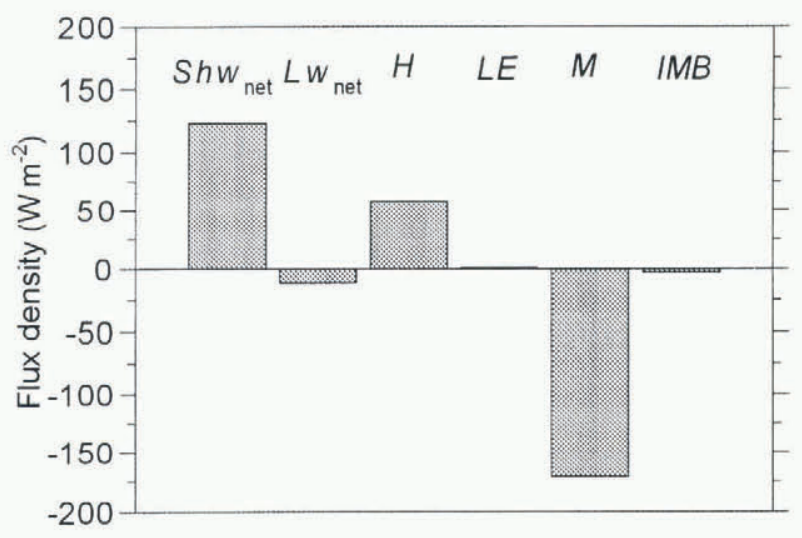

Fig. 8. Energy balance at site 4 during GIMEX-91, based on the upper curve in Figure 7. IMB represents the imbalance between measured and calculated melting energy ( $3 \mathrm{Wm}^{-2}$ or $\left.2 \%\right)$.

melting energy of $16 \%$. Use of the explicit stability correction to calculate the turbulent fluxes results in a $9 \%$ energy shortage. Using $z_{0}$ as determined from profiles $\left(z_{0}=0.08 \mathrm{~cm}\right)$ underestimates the melting energy by $18 \%$. All these deviations are well outside the uncertainty of the ablation measurements and work in the same direction, which excludes the possibility of error cancellation. As was stated in section 3, the use of a parameterization for global incoming radiation yields good results for this data set.

Figure 8 shows the distribution of the different terms in the energy balance, based on calculations represented by the upper curve in Figure 7. Melting is mainly caused by net shortwave radiation $(2 / 3)$ and the sensible-heat flux $(1 / 3)$. These results agree qualitatively with the energy-balance distribution at Qamanârssûp sermia, near Nuuk (Godthåb), at $790 \mathrm{~m}$ a.s.l. (Braithwaite and Olesen, 1990). The quite large contribution of $H$ to the energy balance $\left(58 \mathrm{~W} \mathrm{~m}^{-2}\right)$ can be ascribed to the large aerodynamic roughness of the surface and the persistent katabatic winds. This shows that surface melting in the lower parts of the Greenland ice sheet is probably sensitive to variations in ambient temperature and katabatic wind speed. In this context, it is interesting to note that underestimation of $H$ in meteorological models causes an underestimation of the katabatic wind speed, since this wind is primarily forced by the surface cooling due to the sensible-heat flux (Broeke and others, 1994b). In this study, the contribution of the latent-heat flux $L E$ is very small. It is interesting to note that evaporation (negative latent-heat flux) is generally an important term in the higher ablation zone (Ambach, 1977; Greuell and Konzelmann, 1994; Henneken and others, 1994). Numerical modelling of the energy balance shows that downslope advection of moisture by the katabatic wind forces this term to become small, or even reversed in the lower ablation zone (Broeke, in press).

\section{GONGLUSIONS}

In this paper we presented the energy-balance distribution at a site in the lower melting zone $(340 \mathrm{~m}$ a.s.l.) of the West Greenland ice sheet in summer, based on 86 daily mean observations during GIMEX-90 and 91. The summer climate at this site is warm, dry and sunny, with a seasonal ablation rate of $3.1 \mathrm{~m}$ w.e. Melting is primarily caused by net radiation $(2 / 3)$ and the turbulent flux of sensible heat $(1 / 3)$. The relatively large contribution of the sensible-heat flux (e.g. when compared to midlatitude valley glaciers) can be ascribed to the high albedo, the large aerodynamic roughness and the persistent katabatic winds.

We compared the observations with various parameterizations that are currently used in meteorological and glaciological models. Provided that one knows the surface albedo, the net shortwave radiation can be estimated from cloud cover and surface elevation with sufficient accuracy, using the parameterization presented by Konzelmann and others (1994). On the other hand, if the global radiation is measured, a good estimate of cloudiness can be made using the inverse parameterization. These values are accurate enough to use in longwave radiation calculations or to determine cloud amount as ground truth for satellites. The temperature at $2 \mathrm{~m}$ is no longer an accurate estimate of the temperature of the lower atmosphere when a strong temperature inversion is present above the melting ice, which is the case for the lower ablation zone. As a result, the two parameterizations that were tested in this study underestimated $L W_{\text {in }}$ by as much as $28 \mathrm{Wm}^{2}$. The parameterization by Konzelmann and others (1994) yields slightly better results in the limit of cloud-covered skies through the inclusion of an effective emissivity for overcast conditions. The parameterizations work well higher up on the ice sheet, where the surface inversion is weaker Konzelmann and others, 1994).

Two stability corrections, as well as two different values of $z_{0}$, have been tested to calculate the turbulent fluxes of sensible and latent heat. The observed melt was calculated well if we used the value of $z_{0}$ obtained by microtopographical survey of the terrain $\left(z_{0}=12 \mathrm{~cm}\right)$. The value obtained by profile measurements $\left(z_{0}=0.08 \mathrm{~cm}\right)$ appears to be erroneously small. The explicit stability correction proposed by Louis (1979) underestimates the sensible-heat flux on average by $26 \%$. The turbulent fluxes of latent heat $L E$ were very small in all experiments $\left(<1 \mathrm{Wm}^{2}\right)$. Note that underestimation of $H$ in meteorological models causes an underestimation of the katabatic wind speed, since this wind is primarily forced by the surface cooling due to the sensible-heat flux.

\section{ACKNOWLEDGEMENTS}

R.S.W. van de Wal and two reviewers are thanked for very useful comments on an earlier version of the paper. Financial support for this work was provided by the Dutch National Research Programme on Global Air Pollution and Climate Change (NOP).

\section{REFERENCES}

Ambach, W. 1977. Untersuchungen zum Energieumsatz in der Ablationszone des grönländischen Inlandeises: Nachtrag. Medd. Gronl., 1875 .

Andreas, E. L. 1987. A theory for the scalar roughness and the scalar 
transfer coefficients over snow and sea ice. Boundary-Layer Meteorol., $38(1-2), 159-184$.

Braithwaite, R.J. and O.B. Olesen. 1990. A simple energy-balance model to calculate ice ablation at the margin of the Greenland ice sheet. 7. Glaciol., 36 (123), 222-228.

Broeke, M. R. van den. In press. A bulk model of the atmospheric boundary layer for inclusion in mass balance models of the Greenland ice sheet. Z. Gletscherkd. Glazialgeol.

Broeke, M. R. van den, P. G. Duynkerke and E. A. C. Henneken. 1994a. Heat, momentum and moisture budgets of the katabatic layer over the melting zone of the West Greenland ice sheet in summer. Boundary-Layer Meteorol., 71(4), 393-413.

Broeke, M. R. van den, P. G. Duynkerke and J. Oerlemans, 1994b. The observed katabatic flow at the edge of the Greenland ice sheet during GIMEX-91. Global and Planetary Change, 9(1-2), 3-15.

Duynkerke, P.G. 1991. Radiation fog: a comparison of model simulations with detailed observations. Mon. Weather Rev., 119 (2), 324341.

Duynkerke, P.G. and M.R. van den Broeke. 1994. Surface energy balance and katabatic flow over glacier and tundra during GIMEX91. Global and Planetary Change, 9(1-2), 17-28.

Gallée, H., O. F. de Ghélin and M. R. van den Broeke. 1995. Simulation of atmospheric circulation during the GIMEX-91 experiment using a meso- $\gamma$ primitive equations model. 7. Climate, 8 (11), 2843-2859

Greuell, J. W. and T. Konzelmann. 1994. Numerical modeling of the energy balance and the englacial temperature of the Greenland ice sheet: calculations for the ETH-Camp location (West Greenland, $1155 \mathrm{~m}$ a.s.1.). Global and Planetary Change, 9 (1-2), 91-114.

Henneken, E. A.C., N.J. Bink, H.F. Vugts, F. Cannemeijer and A. G. C. A. Meesters. 1994. A case study of the daily energy balance near the equilibrium line on the Greenland ice sheet. Global and Planetary Change, $9(1-2), 69-78$.

König-Langlo, G. and E. Augstein. 1994. Parameterisation of the downward long-wave radiation at the Earth's surface in polar regions. Meteorol. Z., 3 6), 343-347.

Konzelmann, T. and R.J. Braithwaite. 1995. Variations of ablation, albedo and energy balance at the margin of the Greenland ice sheet, Kronprins Christian Land, eastern North Greenland. f. Glaciol., $41(137), 174-182$.
Konzelmann, T., R.S.W. van de Wal, J.W. Greuell, R. Bintanja, E. A. C. Henneken and A. Abe-Ouchi. 1994. Parameterization of global and longwave incoming radiation for the Greenland ice sheet. Global and Planetary Change, 9(1-2), 143-164.

Lettau, H. 1969. Note on aerodynamic roughness-parameter estimation on the basis of roughness-element description. f. Appl. Meteorol., 8, $828-832$.

Louis, J.F. 1979. A parametric model of vertical eddy fluxes in the atmosphere. Boundary-Layer Meteorol., 17, 187-202.

Meesters, A. G. C. A., E. A. C. Henneken, N.J. Bink, H. F. Vugts and F. Cannemeijer. 1994. Simulation of the atmospheric circulation near the Greenland ice sheet margin. Global and Planetary Change, 9 $(1-2)$, $53-67$.

Munro, D.S. 1989. Surface roughness and bulk heat transfer on a glacier: comparison with eddy correlation. J. Glaciol., 35 (121), 343 348.

Oerlemans, J. 1993. Possible changes in the mass balance of the Greenland and Antarctic ice sheets and their effects on sea level. In Warrick, R. A., E. M. Barrow and T. M. L. Wigley, eds. Climate and sea level change: observations, projections and implications. Cambridge, Cambridge University Press, 144-161.

Oerlemans, J. and H.F. Vugts. 1993. A meteorological experiment in the melting zone of the Greenland ice sheet. Bull. Am. Meteorol. Soc., 74 3) $355-365$.

Ohmura, A. and M. Wild. 1995. A possible change in mass balance of Greenland and Antarctic ice sheets in the coming century. Gronlands Geologiske Undersogelse, Open File 95/5, 59-77.

Wal, R. S. W. van de and J. Oerlemans. 1994. An energy balance model for the Greenland ice sheet. Global and Planetary Change, 9 (1-2), 115 131.

Wal, R.S.W. van de and A.J. Russell. 1994. A comparison of energy balance calculations, measured ablation and meltwater runoff near Sondre Stromfjord, West Greenland. Global and Planetary Change, 9 ( 2), 29-38.

Wal, R.S. W. van de and 11 others. In press. Mass balance measurements in the Sondre Stromfjord area in the period 1990-1994. Z. Gletscherkd. Glazialgeol. 